\title{
Mathematical modeling of heating of coal particle within the space between electrodes of arc-heating reactor
}

\author{
Oleksandr Zhevzhyk ${ }^{1, *}$, Leonid Kholiavchenko ${ }^{2}$, Serhii Davydov ${ }^{2}$, Iryna Potapchuk ${ }^{2}$, \\ Liudmyla Kabakova ${ }^{2}$, Olena Gupalo ${ }^{2,3}$, Vitalii Pertsevyi ${ }^{1}$, and Nataliia Morozova ${ }^{4}$ \\ ${ }^{1}$ Dnipro National University of Railway Transport named after Academician V. Lazaryan, 49010, \\ Dnipro, Lazaryan Str., 2, Ukraine \\ ${ }^{2}$ Institute of Geotechnical Mechanics named by N. Poljakov of National Academy of Sciences of \\ Ukraine, 49005, Dnipro, Simferopolska Str., 2a, Ukraine \\ ${ }^{3}$ National Metallurgical Academy of Ukraine, 49600, Dnipro, Haharina Ave., 4, Ukraine \\ ${ }^{4}$ LLC "CHEMICAL FACTORY "OSNOVA", 49010, Dnipro, Horianaia Str., 2b, Ukraine
}

\begin{abstract}
A mathematical model of heating of coal particles that move in the initial section of a submerged gas jet within the space between electrodes of reaction chamber of arc-heating reactor is created. The model takes into account convective heat transfer and heat transfer by radiation from a sphere (particle) - circle (anode) system. The temperatures of particles on mechanical trajectory are obtained depending on particle diameters and the initial coordinate of nozzle leaving.
\end{abstract}

\section{Introduction}

Today plasma-chemical processes and equipment are widely used in the processing and conversion of dispersed materials in metallurgy, energy, chemistry, in production of construction materials and mineral processing, as well as in the waste disposal and neutralization. Depending on the methods of energy supply into the reaction space, plasmajet reactors (split type reactors) and arc-heating reactors (combined type reactors) are distinguished. These reactors can be used to produce the synthesis gas from carboncontaining raw materials to be used in direct burning of the product (boiler plants) and in closed cycle coal gasification technology for electricity production, in the synthesis of liquid motor fuel, in the production of reducing atmospheres in metallurgy.

Some processes such as atomization of fuel in the reactor chamber, evaporation of water droplets depending on their size, evolution and combustion of volatiles, heating of gas and coke particles in the chamber have been studied in terms of gas temperatures in the reaction chamber of up to $2000 \mathrm{~K}$, and the results are described in $[1,2]$ for the case of the gasification process in a split type reactor. The results of experimental studies of heating of coal particles in boiler reactor are given in [3].

The process of gasification of coke residue at temperatures above $2000 \mathrm{~K}$ is of particular interest since it is known that at high temperatures the rates of chemical reactions

*Corresponding author: zvzk@ukr.net 
and carbon conversion increase significantly [4]. This improves the performance of the gasification process of carbon-containing fuels, hardware intensity and capital costs.

Arc-heating reactor characterized by intense heat transfer due to its predominant radiation component provides a heating rate of dispersed material (for example, coal) up to $10^{6} \mathrm{deg} / \mathrm{s}$ [5] and fast achievement of a final particle temperature. At this temperature level carbon is completely converted to a gaseous state. At the same time, in order to reduce power inputs, ensure the required quality of the main product (synthesis gas) and to avoid overheating, the mineral part must be removed opportunely from the heating zone at temperature of complete carbon conversion of 1800 to $2000 \mathrm{~K}$ [6]. Thus, coal particles must be exposed to heat treatment for a strictly defined time - the particle residence time in the reaction space. Therefore, one of the main processes that affect the subsequent stages of thermal transformation is heating of coal particles.

The choice of the required residence time of the coal particles in the reactor chamber determines the energy intensity of carbon conversion processes and quality (composition and quantity) of main product during gasification. In addition, the residence time significantly affects the geometric parameters of the reaction chamber where the gasification process proceeds. Therefore, the investigation of heat transfer in a reaction archeating chamber is a relevant task, the solution of which makes it possible to choose the necessary geometric parameters of the chamber and its operation mode.

The purpose of the work is to create a mathematical model of heating of coal particles in gas jet that move within the space between electrodes of reaction chamber, and to determine the final temperatures of the particles depending on their diameters and the initial coordinate of nozzle leaving.

\section{Methods}

The scheme of the reaction space of the combined type (reaction chamber) is presented in Figure 1. The cylindrical chamber made of graphite, in which the coal particles 1 are heated, consists of anode 2 and cathode 3 . Electric arc 5 is formed between anode 2 and cathode 3 . The chamber is surrounded by solenoid 6 , which provides rotation of the electric arc and the energy distribution in the reaction space and volumetric heating of the anode.
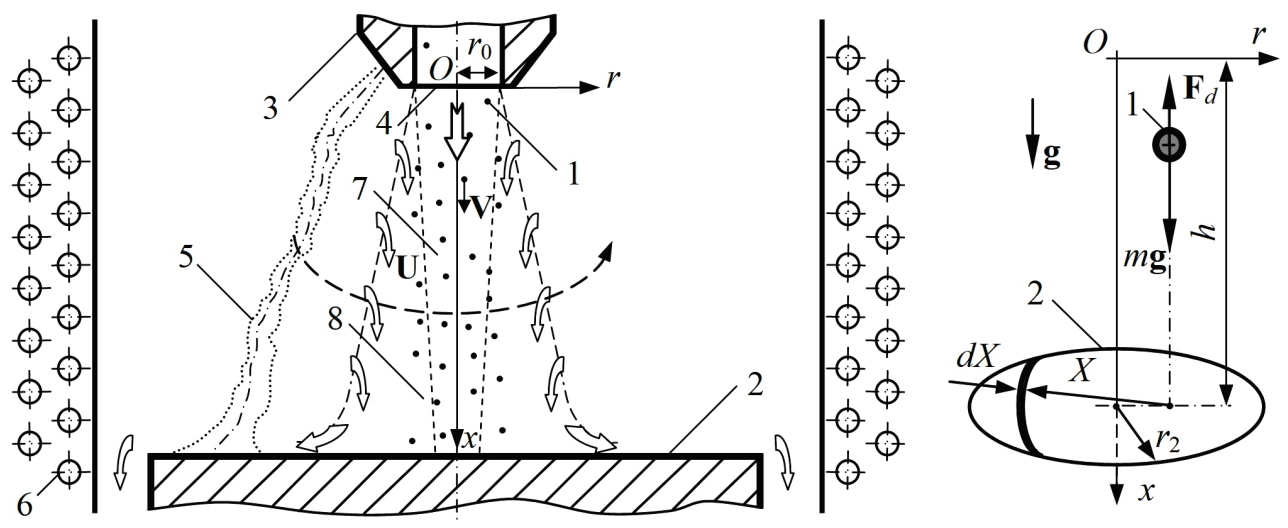

Fig. 1. Scheme for calculating the heating of a coal particle in a reactor.

Coal particles and gas (oxidizing medium) enter the space between electrodes through a nozzle in the cathode 4 of radius $r_{0}$, forming a nonisothermal submerged gas jet [7]. Taken into account the small distance $h$ between the electrodes, heat transfer is mainly realized in the potential core of the initial section of the jet 7 . While moving, the coal particles are heated by radiation from an anode heated by an electric arc (temperature $4200 \mathrm{~K}$ [8]) and 
convective heat exchange with gas in the boundary layer of the mixing zone 8 .

Since the volume concentration of coal dust in the stream in the reactor is less than 0.02 , the particles do not interact with each other [9], and a mathematical model of motion and heat transfer can be created for a single coal particle.

A particle in a gas stream moves under the influence of aerodynamic resistance and gravity. So, the differential equation of motion of the center of mass of the particle has the form:

$$
m \frac{d \mathbf{V}}{d \tau}=\mathbf{F}_{d}+m \mathbf{g}
$$

where $\mathbf{V}$-particle velocity, $\mathrm{m} / \mathrm{s} ; \mathbf{F}_{d}$ - aerodynamic resistance force, $\mathrm{N} ; m=\pi d_{p}{ }^{3} \rho_{p} / 6-$ mass, $\mathrm{kg} ; d_{p}$ - diameter, $\mathrm{m} ; \rho_{p}-$ density of particle, $\mathrm{kg} / \mathrm{m}^{3} ; \mathbf{g}-$ vector of gravity, $\mathrm{m} / \mathrm{s}^{2} ; \tau-$ time, $\mathrm{s}$.

The projection of the aerodynamic resistance force on the axis $x$ is:

$$
F_{d}=-\frac{1}{8} C \cdot \pi d_{p}^{2} \rho_{g}|\mathbf{V}-\mathbf{U}|(V-U)
$$

where $\rho_{g}$ - gas density, $\mathrm{kg} / \mathrm{m}^{3} ; U$ - the gas velocity, $\mathrm{m} / \mathrm{s}$, aerodynamic resistance coefficient is determined by the Reynolds number by the formula [10]:

$$
C=\frac{24}{\operatorname{Re}}+\frac{4.4}{\sqrt{\operatorname{Re}}}+0.32 .
$$

Reynolds number is $\mathrm{Re}=|\mathbf{V}-\mathbf{U}| d_{p} / v$, where $v$ - gas kinematic viscosity, $\mathrm{m}^{2} / \mathrm{s}$.

The enthalpy of a coal particle in a gas stream changes due to radiation from a heated anode and convective heat transfer in the mixing boundary layer. Then for particles with a Biot number less than 1:

$$
m \frac{d i}{d \tau}=Q_{c}+Q_{2-1},
$$

where $i=C_{p} T_{p}$-specific enthalpy, $\mathrm{J} / \mathrm{kg} ; C_{p}$ - specific heat, $\mathrm{J} /(\mathrm{kg} \cdot \mathrm{K}) ; T_{p}-$ particle temperature, $\mathrm{K} ; Q_{c}$ - convective heat flow, W; $Q_{1-2}$ - heat flow by radiation, $\mathrm{W}$.

Convective heat flow according to Newton's law:

$$
Q_{c}=\alpha\left(T_{g}-T_{p}\right) \cdot f
$$

where $\alpha$-average heat transfer coefficient, $\mathrm{W} /\left(\mathrm{m}^{2} \cdot \mathrm{K}\right) ; T_{g}$ - gas temperature, $\mathrm{K} ; f=\pi d_{p}{ }^{2}-$ particle surface area, $\mathrm{m}^{2}$.

To determine the heat transfer coefficient, we use the dependence [11]:

$$
\frac{\alpha d_{p}}{\lambda_{g}}=\mathrm{Nu}=2+0.55 \operatorname{Re}^{0.5} \operatorname{Pr}^{0.33},
$$

where $\mathrm{Nu}$ - Nusselt number, $\mathrm{Pr}-$ Prandtl number, $\lambda_{\mathrm{g}}-$ gas thermal conductivity, $\mathrm{W} /(\mathrm{m} \cdot \mathrm{K})$.

The heat flow by radiation from the anode to the coal particle is determined by the formula:

$$
Q_{2-1}=\varepsilon \sigma\left(T_{2}^{4}-T_{p}^{4}\right) F_{2} \varphi_{2-1}
$$


where $\varepsilon$ - reduced emissivity coefficient; $\sigma$-Stefan-Boltzmann constant, $\mathrm{W} /\left(\mathrm{m}^{2} \cdot \mathrm{K}^{4}\right) ; T_{2}-$ anode surface temperature, $\mathrm{K} ; F_{2}$ - radiating surface area of the anode, $\mathrm{m}^{2} ; \varphi_{2-1}-$ the average angular coefficient of radiation of the anode, which is determined depending on the geometric parameters and the relative placement of anode and particle.

It is assumed that the radiation surfaces of the anode and particles are gray, the effective radiation is diffuse and is characterized by a constant density on isothermal surfaces.

The average angular coefficient of radiation $\varphi_{1-2}$ of a sphere (coal particle), which is located above the circle (anode), is determined by the formula [11]:

$$
\varphi_{1-2}=\frac{1}{2 \pi} \int_{R_{2}-B}^{R_{2}+B} \arccos \left(\frac{X^{2}+B^{2}-R_{2}^{2}}{2 B X}\right) \frac{X}{\sqrt{\left(1+X^{2}\right)^{3}}} d X+\frac{1}{2}\left(1-\frac{1}{\sqrt{1+\left(R_{2}-B\right)^{2}}}\right),
$$

where $B=r /(x-h), R_{2}=r_{2} /(x-h)$ are dimensionless quantities, $r_{2}$ - radius of the anode, $\mathrm{m}$.

Then average angular coefficient of radiation of the anode $\varphi_{2-1}$ can be found using the reciprocity property of the angular coefficients:

$$
\varphi_{1-2} f=\varphi_{2-1} F_{2},
$$

The reduced coefficient of thermal radiation of the anode-particle system is determined depending on their emissitivity factors:

$$
\varepsilon=\left[\left(\frac{1}{\varepsilon_{p}}-1\right) \cdot \varphi_{1-2}+\left(\frac{1}{\varepsilon_{2}}-1\right) \cdot \varphi_{2-1}+1\right]^{-1} \approx\left[\left(\frac{1}{\varepsilon_{p}}-1\right) \cdot \varphi_{1-2}+1\right]^{-1},
$$

where $\varepsilon_{2}$ - emissivity coefficient of anode.

Emissitivity factor of coal particle is determined taking into account a dust level of stream [13]:

$$
\varepsilon_{p}=\frac{1-\exp \left(-0.94 \varepsilon_{1} \pi r_{p}^{2} n D\right)}{\pi r_{p}^{2} n D}
$$

where $\varepsilon_{1}$ - emissivity coefficient of single coal particles; $r_{p}$ - coal particle radius, $\mathrm{m} ; n-$ average number of particles per unit volume, $\mathrm{m}^{-3} ; D=2 r_{0}$ - diameter of a stream where particles are concentrated, $\mathrm{m}$.

To calculate the velocity and temperature of the gas flow in the initial section of the submerged jet, the technique has been used [7]. In the potential core of the jet, the velocity and gas temperature are unchanged and equal to $U_{0}$ and $T_{0}$, respectively, and outside it, in the boundary layer where the jet is mixed, the dependence is:

$$
\frac{U}{U_{0}}=1-\left(1-\eta^{3 / 2}\right)^{2}
$$

where $\quad \eta=1-y_{1} / b+\left(r_{0}-r\right) / b-$ nondimensional coordinate; $b$-boundary layer thickness, $\mathrm{m} ; y_{1} / b$ - internal boundary of the jet mixing zone.

$$
\begin{gathered}
\frac{y_{1}}{b}=\theta\left(A_{1}-2 A_{2}+A_{3}\right), \\
A_{1}=\frac{0.316}{1+0.280\left(\theta^{0.75}-1\right)}, A_{2}=\frac{0.450}{1+0.375\left(\theta^{0.75}-1\right)}, A_{3}=\frac{\ln \theta}{\theta-1},
\end{gathered}
$$




$$
b=0.27 \frac{1+\theta}{2} x
$$

where $\theta=T_{0} / T_{c}$ - gas temperature ratios in nozzle and reactor chamber.

The temperature of the gas stream in the mixing layer:

$$
\frac{T_{0}-T}{T_{0}-T_{c}}=1-\eta
$$

The radial gas velocity in the mathematical model is not taken into account, since it is equal to zero in the potential core of the jet and does not exceed $1-4 \%$ of the longitudinal velocity $U$, which is several times less than the pulsatile velocity of the turbulent stream in the boundary layer [7].

Equations (1) - (14) were supplemented by the temperature dependences of density, kinematic viscosity, heat capacity, gas thermal conductivity as well as the heat capacity of coal particles. For this case the data [13] were approximated by polynomials and a linear dependence was used to determine the heat capacity of coal [15]:

$$
C_{p}=992+0.209 \cdot\left(T_{p}-273.15\right) .
$$

Based on the fact that the particle size of coal does not change does not change significantly, the density is assumed constant $\rho_{p}=1500 \mathrm{~kg} / \mathrm{m}^{3}$.

After the relevant transformations, differential equations (1) and (4) in the projection onto the $x$ axis take the form as follows:

$$
\left\{\begin{array}{l}
\frac{d V}{d \tau}=-\frac{3}{4} \frac{C \cdot \rho_{g}}{d_{p} \rho_{p}}|\mathbf{V}-\mathbf{U}|(V-U)+g \\
\frac{d T_{p}}{d \tau}=\frac{6}{d_{p} \rho_{p} C_{p}}\left[\alpha\left(T_{g}-T_{p}\right)+\varepsilon \sigma\left(T_{2}^{4}-T_{p}^{4}\right) \varphi_{1-2}\right] .
\end{array}\right.
$$

The initial conditions for equations (16) are the stream parameters at the nozzle outlet:

$$
\left.V\right|_{\tau=0}=V_{0},\left.\quad T_{p}\right|_{\tau=0}=T_{0} .
$$

To solve the system of differential equations (16) with initial conditions (17), the fourth-order numerical Runge-Kutta method was used, and the Simpson method was used to calculate a definite integral (8). The calculation accuracy was controlled by the recalculation method with halved step size.

\section{Results and discussion}

The calculations were performed for coal particles with diameters of $d_{p}=50-150 \mu \mathrm{m}$ in a stream of water vapor with an initial temperature of $T_{0}=723.15 \mathrm{~K}$ that are discharged from a nozzle of radius $r_{0}=7 \mathrm{~mm}$ to the reaction chamber at a velocity of $U_{0}=15 \mathrm{~m} / \mathrm{s}$. The emissivity coefficient of coal particles is $\varepsilon_{1}=0.85$. The anode of radius $r_{2}=50 \mathrm{~mm}$ is uniformly heated by an electric arc to $T_{2}=4200 \mathrm{~K}$.

Figure 2 shows the temperature of particles with a diameter of $d_{p}=50 \mu \mathrm{m}$ depending on the coordinate of the mechanical trajectory and the initial coordinate of nozzle leaving. Since the gas outflows from the nozzle as a submerged jet, the particles with the coordinate of the outflow radius (distance from the nozzle axis) $R_{0}<6 \mathrm{~mm}$ most of the time flow in the 
potential core and have approximately the same temperature. In this case, at the trajectory end point $(x=0.07 \mathrm{~m})$, the particle temperature is $T_{p k} \approx 1685 \mathrm{~K}$. Trajectories of particles with $R_{0}=6-7 \mathrm{~mm}$ entrap into the boundary layer of the jet, where they are additionally heated by means of convective heat exchange with gas. The highest particle temperature $T_{p k} \approx 1980 \mathrm{~K}$ is reached out at $R_{0}=7 \mathrm{~mm}$.

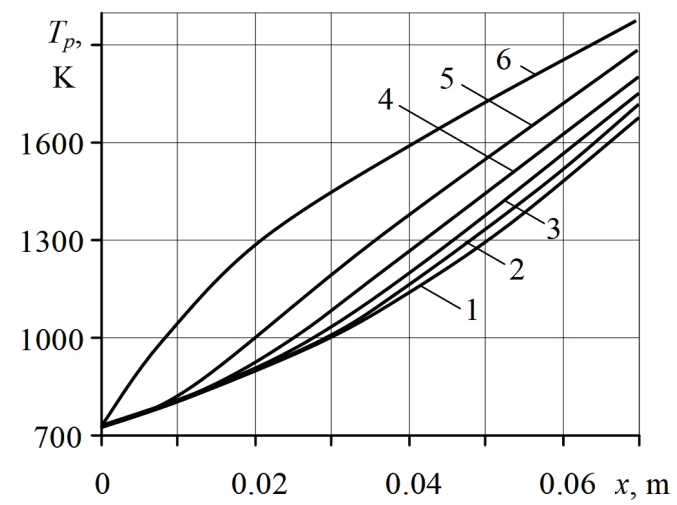

Fig. 2. The temperature of coal particles $d_{p}=50 \mu \mathrm{m}$ on the trajectory and depending on the initial leaving radius: $1-R_{0}<6 \mathrm{~mm}, 2-6.2,3-6.4,4-6.6,5-6.8,6-7.0$.

Figure 3 shows the final temperature of the particles, depending on the initial leaving point $R_{0}=6-7 \mathrm{~mm}$ and their diameters. The diameter of particles, as expected, based on the equations of the mathematical model, largely determines their final temperature. The temperature of particles with a diameter of $d_{p}=100 \mu \mathrm{m}$ is $330-380 \mathrm{~K}$ less, and with a diameter of $d_{p}=150 \mu \mathrm{m}$ it is $520-640 \mathrm{~K}$ less than for particles with a diameter of $50 \mu \mathrm{m}$.

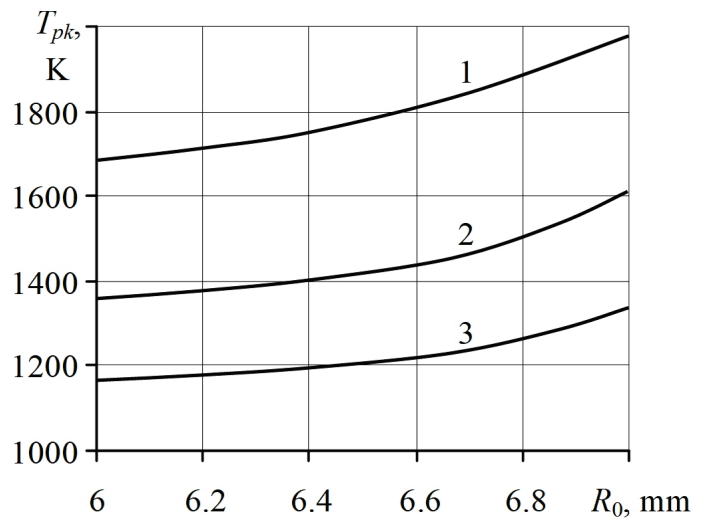

Fig. 3. Final temperature of coal particle for particle diameter: $1-d_{p}=50 \mu \mathrm{m}, 2-100,3-150$.

The temperature of particles that start motion from $R_{0}<6 \mathrm{~mm}$ barely differs from the temperature of particles with $R_{0}=6 \mathrm{~mm}$.

Horizontal axis of Figure 4 shows the final temperature of the particles, in turn vertical axis shows the mass fraction of the particles $\psi$ to the total mass of coal, at this temperature as well as and $R_{0}=6-7 \mathrm{~mm}$. It follows from the calculations that the mass fraction of particles with a diameter of $d_{p}=50 \mu \mathrm{m}$ at a final temperature of $1800 \mathrm{~K}$ or higher is about $16 \%$. 


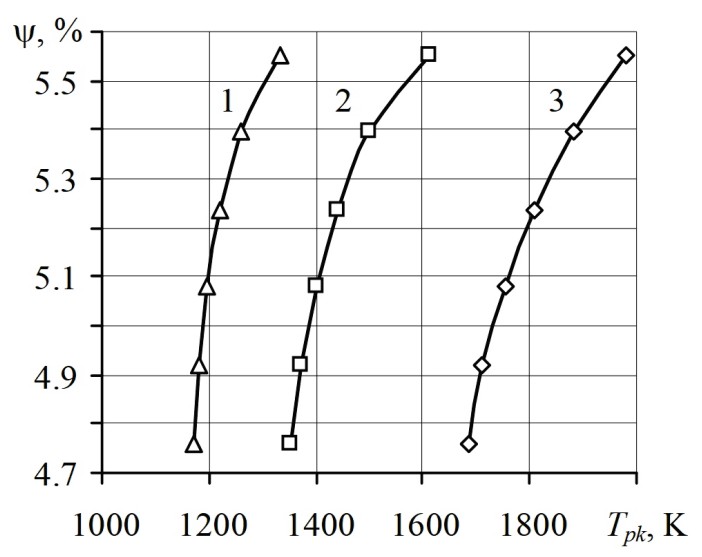

Fig. 4. Mass fraction of coal particles to the total mass of coal with initial radius of leaving trajectory $R_{0}=6-7 \mathrm{~mm}$ and diameter: $1-d_{p}=150 \mu \mathrm{m}, 2-100,3-50$.

\section{Conclusions}

A mathematical model of the heating of coal particles that move within the initial section of the submerged gas jet within the space between the electrodes of the reaction chamber is proposed.

It is necessary to provide a gap between the cathode and anode of $60-70 \mathrm{~mm}$ and dispersion with an average particle diameter of $d_{p} \approx 50 \mu \mathrm{m}$ or less for reaching out temperature for coal particles of $1800 \mathrm{~K}$ and higher.

The final particle temperature substantially depends on the initial point of nozzle leaving.

The mass fraction of particles with a diameter of $d_{p} \approx 50 \mu \mathrm{m}$ to the total mass of coal at a final temperature higher than $1800 \mathrm{~K}$ is about $16 \%$.

The rest of the mass should be heated outside the space between the electrodes within the reaction chamber.

\section{References}

1. Krukovskyi, V.K., Lebedev, V.V., Kolobova, E.A. (1976). Issledovanie protsessa nagreva polidispersnogo uglya vyisokotemperaturnyim gazovyim teplonositelem. Himiya tverdogo topliva, (6), 26-30

2. L. Kholiavchenko, Ye. Pihida, S. Demchenko, S. Davydov. Determination of the kinetic constants of the process of plasma gasification of coal-water fuel. E3S Web of Conferences, International Conference Essays of Mining Science and Practice, 109 (2019). https://doi.org/10.1051/e3sconf/201910900034

3. Bulat, A., Voloshyn, O., Zhevzhik, O. (2013). Plasma reactor for thermochemical preparation of coal-air mixture before its burning in the furnaces. Annual ScientificTechnical Collection - Mining of Mineral Deposits, 39-44

4. V. Yemelianenko, V. Pertsevyi, O. Zhevzhyk, I. Potapchuk, O. Lutai. Experimental study of the thermochemical treatment of the low-grade coal prior to boiler combustion at coal-fired power station. E3S Web of Conferences, International Conference Essays of Mining Science and Practice, 109 (2019). https://doi.org/10.1051/e3sconf/ 201910900119

5. Kholiavchenko, L.T., Pyhyda, E.Yu., Demchenko, S.V. (2016) Himicheskaya kinetika protsessov pererabotki dispersnyih uglerodsoderzhaschih sred $\mathrm{v}$ plazme vodyanogo 
para. Geotehnicheskaya mehanika, (129), 181-189

6. Abramovich, H.N. (2011). Teoriya turbulentnih struy. Moskva: EKOLIT

7. Donskoy, A.V., Kulyashov, S.M. (1961). Elektrotermiya. Moskva- Leningrad: Gosudarstvennoe energeticheskoe izdatelstvo

8. Sou, S. (1971). Gidrodinamika mnogofaznyih sistem. Moskva: Mir

9. Olevskiy, V.A. (1953). Sbornik nauchno-issledovatelskih rabot Nauchnoissledovatelskogo i proektnogo instituta mehanicheskoy obrabotki poleznyih iskopaemyih, (8), 7-43

10. N. Frössling, Gerlands Beitr. Geophys., 52, 170 (1938)

11. Bloh, A.G., Zhuravlev, Yu.A., Ryizhkov, L.N., (1991). Teploobmen izlucheniem. Spravochnik. Moskva: Energoatomizdat

12. A. Goyal, D. Gidaspow, Ind and Eng. Chem. Process. Des. and Develop, 21 (1982)

13. Vargaftik, V.P. (1972). Spravochnik po teplofizicheskim svoystvam gazov i zhidkostey. Moskva: Nauka

14. Pomerantsev, V.V., Arefev, K.M. Ahmedov, D.B. (1986). Osnovyi prakticheskoy teorii goreniya. Leningrad: Energoatomizdat 